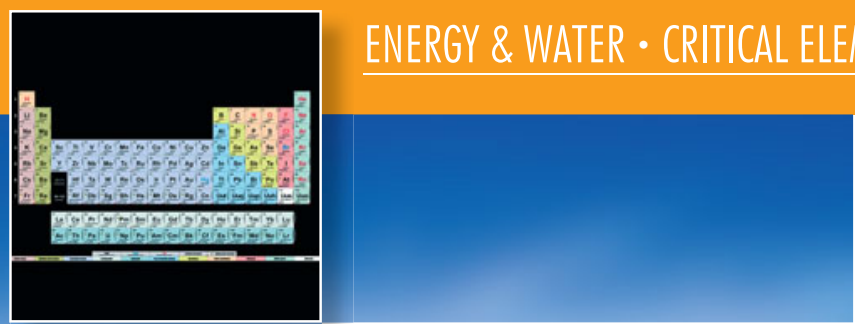

\title{
Energy-critical elements for sustainable development
}

\author{
Alan J. Hurd, Ronald L. Kelley, Roderick G. Eggert, \\ and Min-Ha Lee
}

\begin{abstract}
Energy-critical elements (ECEs) are chemical and isotopic species that are required for emerging sustainable energy sources and that might encounter supply disruptions. An oft-cited example is the rare-earth element neodymium used in high-strength magnets, but elements other than rare earths, for example, helium, are also considered ECEs. The relationships among abundance, markets, and geopolitics that constrain supply are at least as complex as the electronic and nuclear attributes that make ECEs valuable. In an effort to ensure supply for renewable-energy technologies, science decision makers are formulating policies to mitigate supply risk, sometimes without full view of the complexity of important factors, such as unanticipated market responses to policy, society's needs for these elements in the course of basic research, and a lack of substitutes for utterly unique physical properties. This article places ECEs in historical context, highlights relevant market factors, and reviews policy recommendations made by various studies and governments. Actions taken by the United States and other countries are also described. Although availability and scarcity are related, many ECEs are relatively common yet their supply is at risk. Sustainable development requires informed action and cooperation between governments, industries, and researchers.
\end{abstract}

\section{Introduction}

The term "energy-critical elements" (ECEs) was coined by a joint committee of the American Physical Society (APS) and Materials Research Society (MRS) assembled in 2009 to investigate the material resources available to support emerging energy technologies ${ }^{1}$ (see Figure 1). By the time the APS-MRS study was published in 2011, several countries had already started acting on concerns about the supply risk of critical minerals and materials. ${ }^{2}$

In the United States, congressional committee hearings, legislation, and administration studies were initiated. The U.S. Department of Energy released an important report in late $2010^{3}$ and a comprehensive follow-up in late $2011^{4}$ that identified 14 critical elements: cerium, cobalt, dysprosium, europium, gallium, indium, lanthanum, lithium, neodymium, praseodymium, samarium, tellurium, terbium, and yttrium (see Figure 1). These materials were selected based on supply risk factors, including small global market, lack of supply diversity, and market complexities caused by coproduction and geopolitical risks. The
APS-MRS and Department of Energy reports are foundational to U.S. policy and legislative flow.

Also in 2010, Korea and Japan undertook broad programs in research and recycling of rare metals, ${ }^{5}$ and the European Union (EU) issued memoranda establishing a critical-materials list. ${ }^{6}$

The sudden concern over ECEs was touched off by international events occurring over at least a decade. As described below, the United States lost its leadership of the rare-earth markets and by 2002 was effectively out of the business. In its place, China rapidly filled the market niche by tapping underutilized deposits using new mining technology. However, on July 8, 2010, China formally announced a $40 \%$ reduction in its export quota for rare-earth (RE) elements, which sent a shock wave through the markets. By that time, China accounted for more than $95 \%$ of worldwide production of rare-earth oxides. Within weeks, the export price of neodymium, a rareearth metal used in high-strength magnets for windmills and electric-car motors, nearly tripled, and in November 2011, it was some seven times higher than it had been in July 2010

Alan J. Hurd, Los Alamos National Laboratory, Los Alamos, NM, USA; ajhurd@lanl.gov

Ronald L. Kelley, MRS Washington Office and The Livingston Group, Washington, DC, USA; rkelley@livingstongroupdc.com

Roderick G. Eggert, Colorado School of Mines, Golden, CO, USA; reggert@mines.edu

Min-Ha Lee, Korea Institute of Industrial Technology, Cheonan, South Korea; mhlee1@kitech.re.kr

DOI: $10.1557 / \mathrm{mrs} .2012 .54$ 


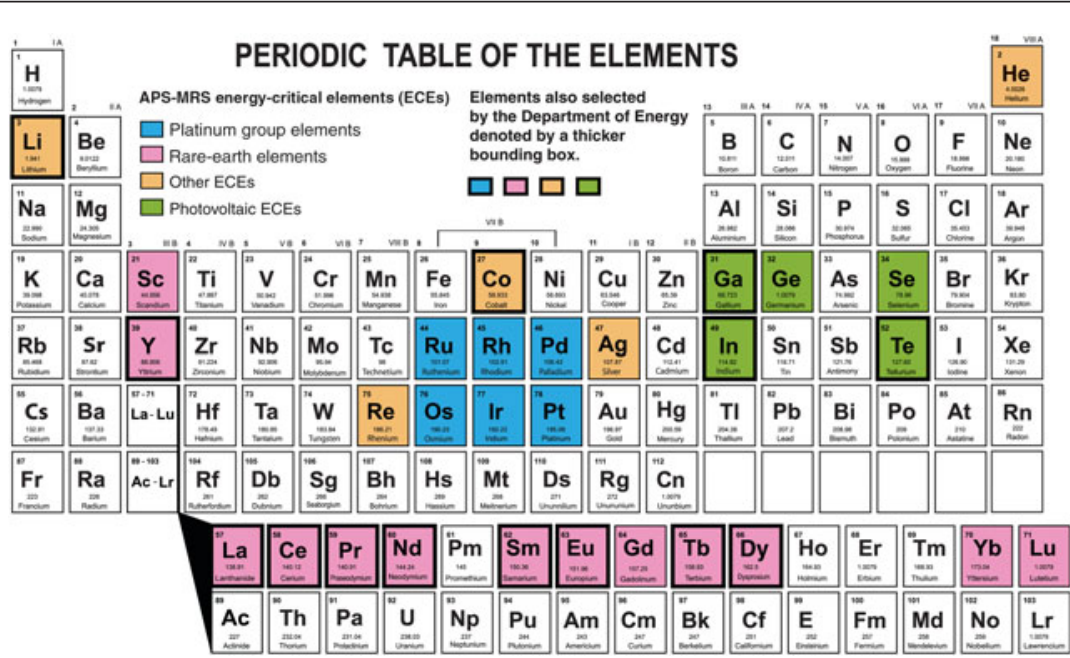

Figure 1. Critical elements chosen by the American Physical Society (APS)-Materials Research Society (MRS) energy-critical element study panel ${ }^{1}$ and by the U.S. Department of Energy Office of Energy Policy. ${ }^{3,4}$ Selection criteria differed in the two studies, leading to 29 elements for the APS-MRS and 14 elements for the U.S. Department of Energy.

Energy-critical elements are not just rare earths

As noted earlier in this issue by Graedel and Erdmann, there are many definitions of critical materials or elements. We confine our comments to energy-critical elements as defined in the APS-MRS study, ${ }^{1}$ unless stated otherwise. ECEs are chemical elements that are necessary for emerging or transformative energy technologies but whose supply risk could limit research, development, or deployment of a technology. Typically, ECEs have not been widely extracted, traded, or utilized in the past and lack a well-established, regulated, or stable market. Non-rare-earth examples include indium for solar cells and energy-efficient displays, tellurium for solar cells and detectors, platinum for novel catalysts, and rhenium for energy-saving superalloys. It is important to appreciate the study's inclusive scope for energy research: research materials such as

(see Figure 2). Regardless of the reason for China's quota action, its effect was to reinforce international concerns about rare-earth elements.

In the wake of these events, the APS-MRS committee published its report on the raw-materials supply risk to emerging energy technologies, including recommended actions. This article reviews that APS-MRS report and others, as well as responses by governments to ECE supply risks. (The article by Graedel and Erdmann in this issue also discusses supply limitations, but of a broader spectrum of metals for manufacturing technologies.) After defining ECEs, we discuss some aspects of their supply chains and markets, U.S. and international policy developments, factors specific to REs and helium, critical-materials lists from selected countries, and the recommendations of the APS-MRS study.

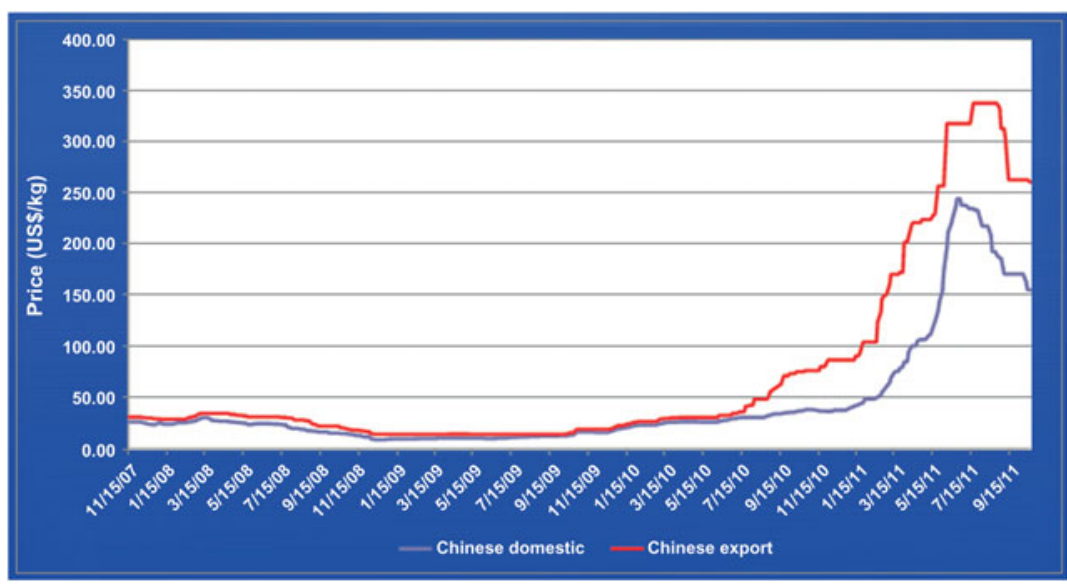

Figure 2. Recent price history of neodymium oxide (2007-2011), as an example of supply risk. Chinese domestic prices (blue line) are less than the Chinese export price for customers outside of China. (From Reference 7 courtesy of the U.S. Geological Survey.) helium for cryogenics can also be "critical" because they are required to develop transformative energy technologies.

ECE lists are neither universal nor constant over time. In 1940, the emerging energy technology was nuclear fission; hence, the ECEs of the day were natural uranium, deuterium, and highly purified graphite, the last two for neutron moderation. Indeed, at that time, committees recommended policies for these then-ECEs, but world events prompted the classification of nuclear policies as national secrets. ${ }^{8}$ Today, uranium, carbon, and deuterium are still critical elements, but they are not energy-critical elements, as they are now governed by highly regulated markets, national security considerations, and public concerns. By 2050, one hopes that progress on sustainable development will likewise have moved some elements off today's ECE lists, perhaps to be replaced by other elements.

By analogy to nuclear power in 1940, today's new or anticipated markets in sustainable energy involving hydro, wind, sea, geothermal, and solar power require a new set of raw materials. Not to be forgotten, however, advanced nuclear reactors are considered by many as a sustainable technology. (See the article in this issue by Englert et al.) Low environmental impact throughout a material's life cycle is a key to sustainability for any ECE supply.

\section{Rare earths}

Despite their name, rare-earth elements are not rare; they are just rarely used. If society is able to adopt new, contemplated energy infrastructure, as well as improved processes for extracting and recovering rare earths, this will change. 
The special electronic and optical properties that make REs useful derive from their unique $4 f$ electrons, which cause the "lanthanide contraction" of ionic radii due to comparatively ineffective screening of the nuclear charge. Because the $4 f$ electrons hug the nucleus, higher-shell electrons in the $5 \mathrm{~s}$ and $6 s$ orbitals are left to interact with other atoms. Therein lie the complex electronic behaviors that endow neodymium with powerful magnetism and europium with unique optical interactions, indispensible for lightweight electric motors and energy-efficient lighting, respectively.

Crustal abundance is one factor in the economics of element extraction, and enrichment into ore bodies is another (see Figure 3). Owing to their unique chemistry, rare earths are not efficiently mineralized by geological processes into concentrated ores. However, when geologically concentrated, they occur together (often partitioned into "light" and "heavy" rare-earth ore bodies) and sometimes with more lucrative commodity metals, such as iron, uranium, and niobium; therefore, they are mostly coproduced as byproducts of the mining of those metals. Because they are difficult to separate from host minerals, often including radioactive uranium and thorium, REs can have high environmental impacts in mining and extraction.

The near-monopoly in RE mining achieved by China by 2009 was enabled in part by the invention of an innovative separation technique requiring low capitalization that opened low-grade ion-absorbed clays to economic production. ${ }^{9}$ Numerous small mines practiced this hydraulic mining process under previous regulations, and even now, it accounts for about $35 \%$ of China's RE production. ${ }^{10}$ Using hydraulic water pressure in

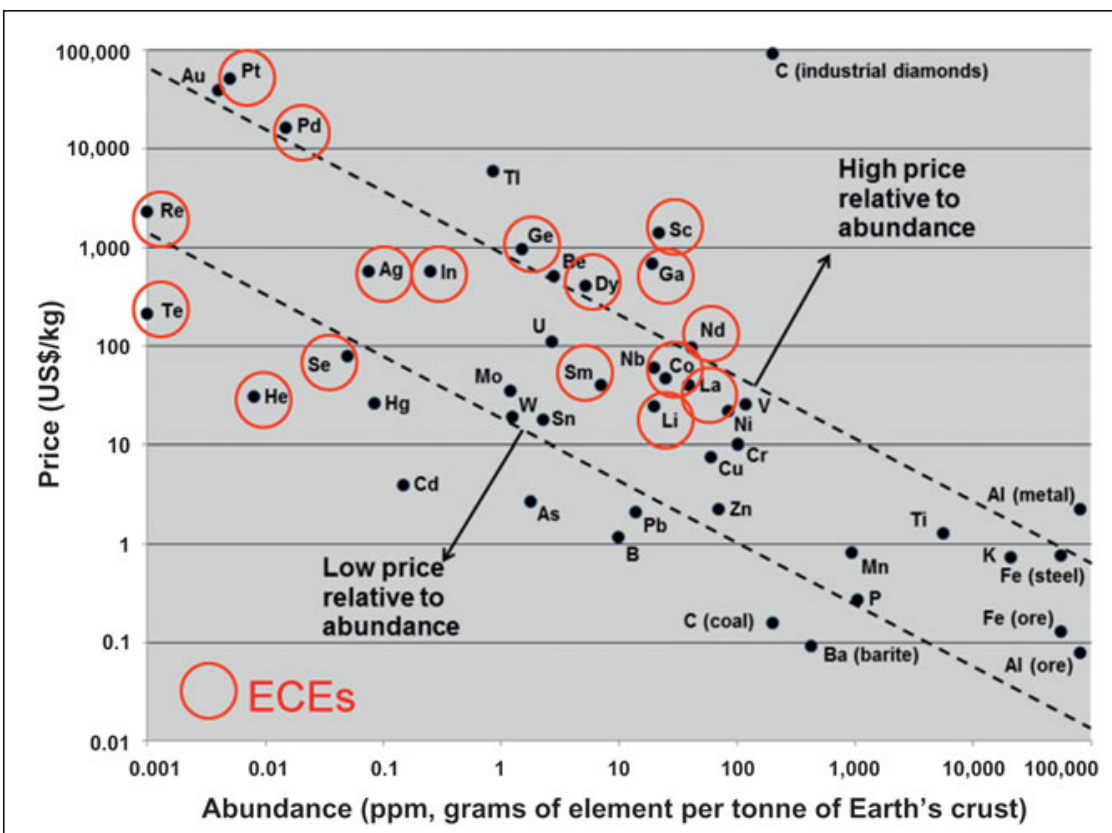

Figure 3. Price-abundance plot for many elements, specifically those for which there is a market. Energy-critical elements are circled in red. (From J. Price, personal communication, who derived the data from various sources, including the CRC Handbook of Chemistry and Physics, the U.S. Geological Survey, and the U.S. Energy Information Administration.) vegetation-cleared hills, the whitish-colored clay is washed into pits lined with plastic. Sulfuric acid or ammonium sulfate is added to dissolve the desired minerals, and then the fluids are siphoned downhill into a concrete pool where they are treated with oxalic acid. Rare-earth oxalates precipitate out and are calcined to oxides in a kiln. In an important final step, the depleted fluids are washed into rivers (in unregulated operations). Thus, river contamination and erosion are two impacts of mining ion-absorbed clays. ${ }^{9}$ Minimizing environmental impacts was a contributing factor in China's revised RE export policy, as noted in the section Actions in Europe and Asia.

Afghanistan reportedly contains rich sources of REs. ${ }^{11}$ Prospecting by Soviet geologists during their intervention in the early 1980s established several promising sites in the country's rugged interior. Over the period from 2004 to 2011, under heavy security provided by the U.S. Armed Forces, geologists from the U.S. Geological Survey confirmed the Russian findings and estimated resources when possible. A Chinese company had already contracted in 2011 to invest $\$ 2.4$ billion in a copper mine in Afghanistan and associated transportation infrastructure. Further development by mining entities awaits political stabilization.

\section{Helium}

Because helium has utterly unique physical attributes, it could be considered an ECE solely by virtue of its value to energy research as a cryogenic fluid. Helium has technological uses important to emerging energy technologies as well. In some advanced nuclear reactor concepts, helium offers unmatched heat conduction while resisting nuclear activation. It serves as a shroud gas for welding, an inert processing gas in semiconductor manufacturing, a cryogen for medical magnetic resonance imaging, and an indispensible flushing agent for liquid-oxygen lines in rocket motors.

Contradictorily, helium is the second most common atom in the universe, but it is among the rarest (by weight) of all elements in the Earth's crust. It has been stockpiled by the United States since 1925, yet helium is so inexpensive that it fills party balloons. The APS-MRS study panel concluded, however, that the helium supply is dangerously at-risk within the time frame for attaining global energy sustainability. In addition, helium serves as a useful cautionary tale of government market interventions. Hence, it was identified as an ECE by the panel even though no other similar study considered it in the energy context. ${ }^{1,12,13}$

The issue with helium is that it is not gravitationally bound to Earth. Generated as a radioactive decay product in Earth's interior, helium is mobile enough to collect, conveniently for our uses, in natural gas reservoirs. However, once released to the atmosphere, helium escapes into space and is essentially lost to humanity. Most 
of the time, it is simply released during natural gas recovery processes as unwanted waste.

In 1925, anticipating strategic military uses such as dirigibles, the United States created the Federal Helium Reserve in a natural structural dome under Amarillo, TX. During the Cold War, the U.S. strategic-missile fleet required ample helium flushing gas to be ready at all times. By 1970, the stockpile exceeded one billion cubic meters - a projected 50-year supply - hence, the government ceased buying more gas. After the demise of the Soviet Union, the U.S. Congress decided in 1996 that the full reserve was no longer needed, so it enacted legislation to sell off almost all federally owned helium gas by 2015 to repay the costs of the reserve itself. Unexpectedly, prices rose after the federal selloff began owing to unanticipated demand from the high-technology sector in developing countries and to increased production and compliance costs in the United States. The selling of federal helium, even at prices significantly higher than private helium stocks, depressed U.S. helium prices relative to foreign gas and, in combination with higher production costs, disadvantaged U.S. producers.

The helium case was the prime stockpiling example the APS-MRS study panel encountered in which government market intervention created market instabilities. Because of this example, the panel recommended against market interventions in general, including stockpiling. However, because helium has unique physical properties that are indispensible in research, medicine, and, for now, in national security, the panel felt that helium should be stockpiled despite market instabilities.

At this writing, a bill is working through U.S. Senate committees to prescribe steps for a sustainable future in U.S. helium supplies. The bill encourages private development of new sources while ensuring ample supplies for research needs.

\section{Actions taken by governments}

Even before China formally announced its intent to cut exports of REs in the summer of 2010, U.S. government agencies were monitoring the supply risk. The heightened attention to REs in energy, defense, and electronic applications increased awareness by the public and the press of U.S. dependency on other countries for specific critical elements.

The APS-MRS energy-critical elements policy study panel convened workshops and interviews with stakeholders in the field. Meanwhile, the Washington, DC, offices of both APS and MRS monitored, and later directly participated in, the development of some of the legislative bills, and these offices provided their respective society's federal interface.

This section also discusses actions taken by several European and Asian countries.

\section{U.S. legislation}

During 2011, a variety of related bills were drafted and introduced to relevant congressional committees for consideration.
At this writing, none of these bills have passed their full respective chambers. This pattern is very common when more than one congressional cycle is required to pass authorization bills.

Of the various minerals- and materials-related bills to be drafted and considered by Congress, RE legislation is the most common type. The issues covered by the broad term "critical minerals and materials" have not yet been fully recognized as a high priority. In part, this is because the media have discussed concerns regarding price, availability, and foreign control primarily with respect to REs without noting that ECEs of all types face similar supply risks.

\section{Broad differences in bills}

Some of the proposed legislation calls for studies for additional information, for example, H.R. 1314 and H.R. 2011. A few of the bills support a particular interest by a member of Congress on behalf of his or her constituents and, in some cases, the desire to impact the mining or rare-earth industry, including H.R.1388, H.R.618, S.383, and S.1113. The closest bill that contains a legislative agenda similar to the recommendations of the APS-MRS energy-critical elements study is H.R.2090. A broader bill, H.R.952, addresses a previous minerals and materials act while adding updates that are needed to address current concerns. Interested readers can review the details in any of these specific bills by going to the Library of Congress "Thomas" web site ${ }^{14}$ and searching for the 2011 bills by their respective numbers. Each of the bills will need to be reintroduced with a new bill number in 2012 and essentially restarted through the legislative process.

Some of the bills emphasize substitution research, recycling, and improved information gathering and dissemination for ECEs and REs. Other bills or components of some bills are focused on revitalizing the mining industry in specialty minerals and materials. Some of the legislative efforts are directed at encouraging investment by government and industry in the value-added chain of products that use ECEs and REs such as magnets, solar cells, wind turbine blades, and batteries.

Legislators have recognized that centers of expertise and professional talent in these difficult scientific areas are critical to sustainability success. The U.S. administration has proposed an energy center devoted to critical minerals and materials as a portion of its fiscal year 2012 Department of Energy budget request. As recommended in the APS-MRS study, a number of bills acknowledge the critical and unmet need of having the federal government more involved in providing credible information on the rapidly changing availability and applications for REs and ECEs. Which specific agency should purvey this information and expertise is a point of debate.

\section{Interest in APS-MRS policy study and outlook for 2012}

One of the most interesting outcomes of the APS-MRS study ${ }^{1}$ has been the attention paid to it by senior leaders in both the legislative and executive branches of the U.S. federal government. In 2011, a number of briefings and meetings were arranged 
for the co-chairs of the policy study, Dr. Robert Jaffe of the Massachusetts Institute of Technology and Dr. Jonathan Price of the University of Reno, NV, who is also the State Geologist for Nevada. They testified directly to House and Senate committees in hearings on REs and critical materials. Staff crafting legislation used the resources of professional societies and asked for input from the ECE study panel. Other members of the study panel provided congressional testimony, including Dr. Karl Gschneidner, of Ames Laboratory and Iowa State University, and one of us (Eggert).

Remarkably, one recommendation from the APS-MRS study was implemented within weeks of the study's February 2011 publication. The study recommended that a high-level formal group, beyond a task force, be established in the National Science and Technology Council to follow issues related to ECEs.

Members of the study panel also made presentations to the White House Office of Science and Technology Policy, Department of Defense, Department of Energy, and other groups within the administration interested in these topics. In addition to briefings with staff from all of the relevant committees in the House and Senate, the ECE report gave MRS and APS an opportunity to interact with many groups in Washington that had policy interests in ECEs, including the MIT Washington Office, American Enterprise Institute, TransAtlantic Business Dialogue, and Heritage Foundation.

The topic will continue to gain attention in Washington, DC, in 2012, even in an election year. As with many topics that are of interest to Congress and Washington, however, the amount of priority time given to the subject will depend on evolving market and global conditions, China-U.S. relations, and general export control of China's REs. If producers and suppliers continue to make supply-risk mitigation a priority for the 112th Congress in the second session, the issue of ECEs will continue to gain momentum in 2012, and final legislation will result.

\section{Actions in Europe and Asia}

China's publicly stated motives for restricting exports of REs were to regulate domestic mines, to encourage development of foreign resources, to control illegal mining, to reduce environmental impacts, and to evolve China from an external supplier to an internal supplier. ${ }^{15}$ Some in the West have speculated that China also wishes to stockpile some ECEs. ${ }^{16}$

The European Union established the Raw Materials Initiative and named 14 mineral groups as critical. ${ }^{6}$ Canada adopted the EU report as well. In addition to sharing most of the elements in the ECE list except helium, tellurium, silver, rhenium, and lithium, the EU list includes antimony, beryllium, magnesium, tungsten, tantalum, and niobium and the minerals fluorspar (fluorite, $\mathrm{CaF}_{2}$ ) and graphite. The EU list is based on an analysis of projected demand for emerging technologies in 2030 compared to 2006. Gallium and indium are expected to exhibit the largest increases, according to the EU analysis. The EU initiative calls for updating the critical raw-materials list every five years, improving statistical information about resources in an annual yearbook, and researching life-cycle assessments and demand for emerging technologies. Additional research is recommended in mineral engineering, exploration, and substitution.

A novel supply-risk analysis with an emphasis on instability underwrites South Korea's list of 56 elements required for domestic use, microelectronics manufacturing, and energy technologies. This large list covers most of the ECEs, but like the EU report, it omits helium as critical. The South Korean analysis ${ }^{5}$ considers rarity, geopolitical supply factors, and recent price variations. In 2007, the platinum-group metals were rated as most rare, REs as most unstable in supply, and selenium as most unstable in price.

The South Korean program emphasizes research in raremetal science; in fact, the Korea Institute for Rare Metals in Incheon was created for this very purpose. In addition, Korea has reached out to the international community to co-develop strategy and perspectives for rare metals.

In Japan, a comprehensive program of recycling, reuse, replacement, reduction in consumption, and stockpiling is underway. Having been the apparent targets of China's reduced export quotas in 2010, Japan ${ }^{5}$ emphasizes new sources of minerals and their concomitant diplomatic relationships.

\section{Recommendations and outlook}

This article draws on studies of critical materials and programs established by governments to ensure stable supplies of elements required to achieve global sustainability in energy. Because the necessary technologies require a great deal of research, we have adopted the APS-MRS study on energy-critical elements as a baseline.

The recommendations by the study panel, paraphrased below, speak to both governments and the international research community.

- Federal agency coordination. The Office of Science and Technology Policy should create a subcommittee within the National Science and Technology Council to examine the production and use of ECEs within the United States and to coordinate the federal response. This action was completed in early 2011 .

- Information collection, analysis, and dissemination. The U.S. government should gather, analyze, and disseminate information on ECEs across the mineral supply chain, from cradle to grave, as a "Principal Statistical Agency" with survey enforcement authority. The federal government should regularly survey emerging energy technologies to identify critical applications and shortfalls.

- Research, development, and workforce enhancement. The federal government should establish a research and development effort focused on ECEs and possible substitutes.

- Efficient use of materials. The government should establish a consumer-oriented "Critical Materials" designation for ECE-related products and a recycling program. 


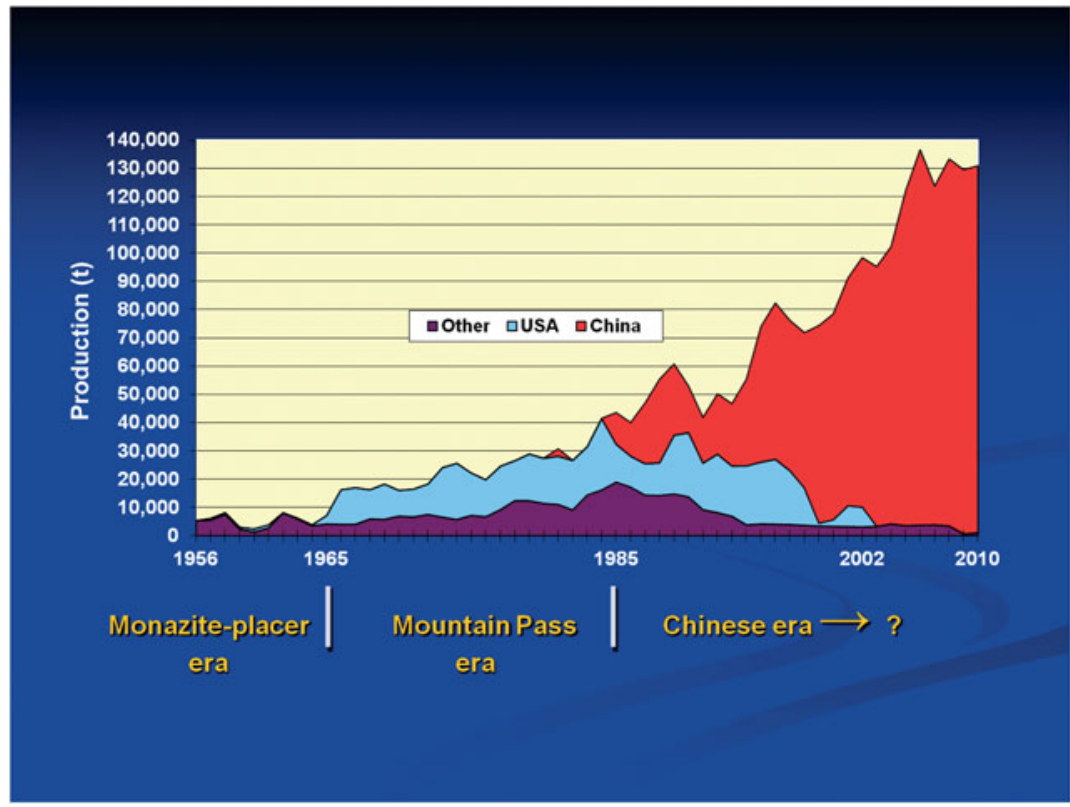

Figure 4. Global production of rare-earth oxides. The Mountain Pass Mine in the U.S. state of California dominated world production of rare earths through 1985, when Chinese production, particularly at the Bayan Obo Mine in Inner Mongolia, became a factor. In 2010, China supplied $97 \%$ of the market. (From Reference 17 courtesy of the U.S. Geological Survey.) with the mine's RE ores. Processing of legacy tailings started in 2009, along with new mining production in 2011. Further, Molycorp plans to scale up production over the next year or so.

The reopening of the Mountain Pass mine is the result of changes in China-where the advantage of mining ion-adsorbed clays by environmentally damaging techniques is being reduced by Chinese policy - and in the United States. Molycorp has devoted significant effort to minimizing the environmental damages associated with RE mining and mineral processing. With this success as an example, other mines, including urban mines, promise a sustainable future pathway paved by materials research.

\section{Acknowledgments}

This work benefited from the Santa Fe Institute and the Lujan Neutron Scattering Center at Los Alamos National Laboratory funded by the U.S. Department of Energy's Office of Basic Energy Sciences (Contracts DE-AC52-06NA25396 and LA-UR 11-06728).
- Market interventions. With the exception of helium, government should avoid interventions in markets including non-defense-related economic stockpiles.

Helium is unique even among ECEs. Measures should be adopted that will both conserve and enhance the nation's helium reserves. Draft legislation for helium was circulated in October 2011.

Supply risks of ECEs involve geopolitical factors. China's near-monopoly in 2011 and Afghanistan's promise as a future supplier imply precarious supply for some consumers. Sustainable supply is not guaranteed to all societies involved in creating the future energy infrastructure. Publicly, at least, major stakeholder countries now strive to balance natural and urban mining to achieve approximate sustainability.

Although REs are far from the whole story of ECEs, society's industrial pressure for REs has led to a useful paradigm in new supply-chain development as illustrated by California's Mountain Pass mine (see Figure 4). Although discovered as a uranium deposit in 1949, the Mountain Pass mine was opened as an RE mine in 1952 and was the dominant RE producer through the 1980s. However, by 2002, the overwhelming price advantage of Chinese suppliersalong with regulatory compliance issues associated with the mine's faintly radioactive tailings and process waterforced closure. By 2011, owner Molycorp became licensed to handle radioactive trace thorium and uranium associated

\section{References}

1. Energy Critical Elements: Securing Materials for Emerging Technologies (Materials Research Society/American Physical Society, Washington, DC, 2011). 2. A. Evans-Pritchard, "World Faces Hi-Tech Crunch As China Eyes Ban on Rare Metal Exports," New York Times (24 August 2009).

3. Critical Materials Strategy (U.S. Department of Energy, Washington, DC, December 2010), energy.gov/sites/prod/files/piprod/documents/cms_dec_17_full_ web.pdf (accessed February 2012)

4. Critical Materials Strategy (U.S. Department of Energy, Washington, DC, December 2011), energy.gov/sites/prod/files/DOE_CMS2011_FINAL_Full.pdf (accessed February 2012).

5. J.-C. Bae, "Strategies and Perspectives for Securing Rare Metals in Korea," presented at the MIT Energy Workshop on Critical Elements for New Energy Technologies, Cambridge, MA, 29 April 2010.

6. Critical raw materials for the EU: Report of the Ad-hoc Working Group on defining critical raw materials (European Commission, Brussels, Belgium, 2010). 7. "Rare Earths: Statistics and Information" (U.S. Geological Survey, Reston, VA), minerals.usgs.gov/minerals/pubs/commodity/rare_earths/ (accessed February 2012). 8. R. Rhodes, The Making of the Atomic Bomb (Simon \& Schuster, New York, 1986).

9. N. Mariano, paper presented at the MIT Energy Workshop on Critical Elements for New Energy Technologies, Cambridge, MA, 29 April 2010.

10. Minerals, Critical Minerals, and the U.S. Economy (National Academies Press, Washington, DC, 2008).

11. S. Simpson, Sci. Am. 58 (October 2011)

12. The Impact of Selling the Federal Helium Reserve (National Academies Press, Washington, DC, 2000).

13. Selling the National Helium Reserve (National Academies Press, Washington, DC, 2011).

14. The Library of Congress, Thomas Home page, thomas.gov (accessed February 2012).

15. Z. Yan, "Suspension Set to Make Rare Earths Even Rarer," China Daily (USA) (19 October 2011).

16. G.P. Hatch, China's Rare Earths Game Plan: Part 1-The Effects Of Reduced Export Quotas (Technology Metals Research, LLC, Carpentersville, IL, 2010). 17. "Global Rare Earth Oxide (REO) Production Trends" (U.S. Geological Survey, Reston, VA), minerals. usgs.gov/minerals/pubs/commodity/rare earths/ree-trends2010.pdf (accessed February 2012). 


\section{ADVANGED ENERGY MATERIALS}

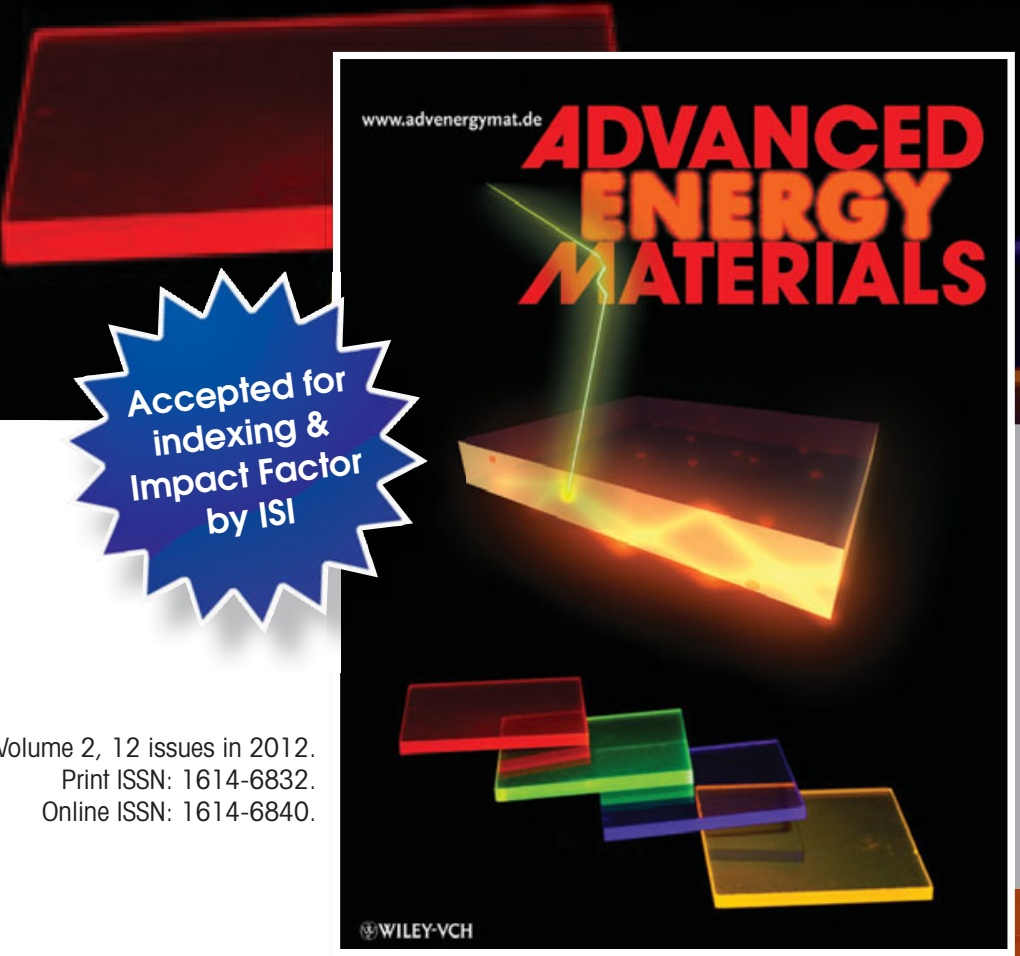

\section{Scope}

Advanced Energy Materials is an international, interdisciplinary, English-language journal of original peer-reviewed contributions on materials used in all forms of energy harvesting, conversion and storage.

\section{Advanced Energy Materials covers} all topics in energy-related research:

- all photovoltaics and artificial photosynthesis

batteries and supercapacitors

ruel cells and biofuel cells

rhydrogen generation and storage

thermoelectrics, magnetocalorics, and more

\section{Don't miss the opportunity to receive} COMPLIMENTARY ONLINE ACCESS

$$
\text { until the end of } 2012 .
$$

Reports, high-impact Full Papers, and rapid Communications.

- Advanced Energy Materials is committed to swift processing and publication of contributions: Using the new Advanced Materials online page proofing system, the editor and the publisher aim to publish papers online within ten weeks of submission.

- Advanced Energy Materials is read by materials scientists, chemists, physicists and engineers in academia as well as industry.

\section{Editorial Advisory Board}

\section{Christoph Brabec (Chair)}

Manfred Waidhas (Chair)

Peter Bruce

Jaephil Cho

Anne C. Dillon

Bruce Dunn

Alan J. Heeger

Wenping $\mathrm{Hu}$

John T. S. Irvine

René A. J. Janssen

Hagen Klauk

Frederik C. Krebs

Karl Leo
Max Lu

David B. Mitzi

Peter H. L. Notten

John A. Rogers

Debra Rolison

Gregory D. Scholes

Henning Sirringhaus

Takao Someya

Michael Strano

Zhonglin Wang

Martin Winter

Dongyuan Zhao

\section{Editorial Office}

Advanced Energy Materials is handled by the experienced Advanced Materials and Advanced Functional Materials editorial team at Wiley-VCH.

\section{Submit your work now!}

Submit your manuscript for Advanced Energy Materials

$$
\text { online via Www.manuscripłXpress.com }
$$

Manuscripts emphasizing the demonstration of applications, exploring structure-property relationships and addressing fabrication issues are particularly welcome. 